\title{
ANALIZA I OCENA RYZYKA ŻELBETOWYCH KONSTRUKCJI SZKIELETOWYCH SPOWODOWANEGO ZDARZENIAMI EKSTREMALNYMI
}

\begin{abstract}
Analizując statystyki związane z katastrofami budowlanymi w Polsce można dojść do wniosku, że najczęstszymi przyczynami katastrof są zdarzenia ekstremalne bardzo rzadko występujące i trudne do przewidzenia. Zdarzenia te nie są bezpośrednio uwzględniane na etapie projektowania konstrukcji ze względu na ich małe prawdopodobieństwo wystąpienia. W obiektach użyteczności publicznej i obiektach zamieszkania zbiorowego zalecane jest przeprowadzenie analizy ryzyka związanego z takimi zdarzeniami ekstremalnymi, których wystąpienie powoduje zniszczenia znacznej części lub nawet całej konstrukcji. W artykule przedstawiono koncepcję procedury oceny i analizy ryzyka obiektów o żelbetowej konstrukcji szkieletowej - ustroju często stosowanego w budownictwie mieszkaniowym i budynkach użyteczności publicznej. Ryzyko przedstawiono jako parametr wyznaczający odporność konstrukcji na zdarzenia ekstremalne jest funkcją wystąpienia zagrożenia oraz poniesionych konsekwencji. Czynniki ryzyka przedstawiono jako wielkości rozmyte ze względu na trudności z ich jednoznacznym określeniem i dokładnym oszacowaniem.
\end{abstract}

Słowa kluczowe: jakościowa ocena ryzyka, ilościowa ocena ryzyka, czynniki ryzyka, żelbetowe konstrukcje szkieletowe

\section{Wstęp}

Analizując dane dotyczące katastrof budowlanych w Polsce gromadzone przez GUNB [8] i ITB [2] można dojść się do wniosku, że najczęstszymi przyczynami katastrof budowlanych są zdarzenia ekstremalne - występujące niezwykle rzadko, często trudne do przewidzenia i nie uwzględniane na etapie projektowania. Ich skutki kojarzone są z obciążeniami wyjątkowymi (wynikającymi z mało prawdopodobnych zdarzeń) opisanymi w EC 1 części 1-7 [7]. Zdarzenia ekstremalne tworzą jednak szerszą grupę, zawierającą zarówno przewidywalne,

\footnotetext{
${ }^{1}$ Kamil Szylak, Politechnika Rzeszowska im. Ignacego Łukasiewicza, Katedra Konstrukcji Budowlanych, ul. Poznańska 2, kszylak@prz.edu.pl
} 
jak i nieprzewidywalne zagrożenia. W obiektach użyteczności publicznej i obiektach zamieszkania zbiorowego (budynki klas konsekwencji 2 b i 3 [7]) zalecane jest prowadzenie analizy ryzyka związanego z tymi zagrożeniami, których wystąpienie powoduje zniszczenie części lub całości konstrukcji. Eurokod 1 część 1-7 [7] zaleca dwie metody analizy ryzyka dotyczącego budynków:

1) Analiza jakościowa - polega na zidentyfikowaniu zagrożeń, odpowiadających im możliwych scenariuszy oddziaływań, a także sposobu użytkowania konstrukcji. Ma to na celu wykazanie, że następstwa spowodowane wystąpieniem zagrożenia są akceptowalne dla bezpieczeństwa konstrukcji. Opracowano wiele technik wspomagających jakościową analizę ryzyka: PHA, HAZOP, drzewo zdarzeń, drzewo błędu czy sieci przyczynowe [1,4,5].

2) Analiza ilościowa - opiera się na obliczeniu ryzyka za pomocą formuły zalecanej w normie ISO 13824 [3] i Eurokodzie 1 części 1-7 [7]:

$$
\mathrm{R}=\sum_{\mathrm{i}=1}^{\mathrm{N}_{\mathrm{H}}} \mathrm{p}\left(\mathrm{H}_{\mathrm{i}}\right) \sum_{\mathrm{j}}^{\mathrm{N}_{\mathrm{D}}} \sum_{\mathrm{k}=1}^{\mathrm{N}_{\mathrm{S}}} \mathrm{p}\left(\mathrm{D}_{\mathrm{j}} \mid \mathrm{H}_{\mathrm{i}}\right) \mathrm{p}\left(\mathrm{S}_{\mathrm{k}} \mid \mathrm{D}_{\mathrm{j}}\right) \mathrm{C}\left(\mathrm{S}_{\mathrm{k}}\right)
$$

gdzie: $\mathrm{N}_{\mathrm{H}}$ - liczba zagrożeń, $\mathrm{N}_{\mathrm{D}}$ - liczba sposobów zachowania się uszkodzonej konstrukcji, $\mathrm{N}_{\mathrm{S}}$ - liczba niekorzystnych stanów konstrukcji po uszkodzeniu, $\mathrm{C}\left(\mathrm{S}_{\mathrm{k}}\right)$ - konsekwencje wystąpienia niekorzystnego stanu, $\mathrm{p}\left(\mathrm{H}_{\mathrm{i}}\right)$ - prawdopodobieństwo wystąpienia i-tego zagrożenia, $p\left(\mathrm{D}_{\mathrm{j}} \mid \mathrm{H}_{\mathrm{i}}\right)$ - prawdopodobieństwo warunkowe j-tego stanu uszkodzenia konstrukcji spowodowanego przez i-te zagrożenie, $\mathrm{p}\left(\mathrm{S}_{\mathrm{k}} \mid \mathrm{D}_{\mathrm{j}}\right)$ - prawdopodobieństwo warunkowe k-tego niekorzystnego zachowania konstrukcji $S_{k}$ powodującego j-ty stan uszkodzenia $[3,4,7]$.

\section{Koncepcja procedury oceny i analizy ryzyka}

\subsection{Procedura analizy i oceny ryzyka}

Ryzyko zniszczenia konstrukcji $\mathbf{R}[5,9,10]$ zdefiniowano jako miarę kombinacji prawdopodobieństw wystąpienia zidentyfikowanych zagrożeń i ich konsekwencji wyrażonych jako część kosztu inwestycji w całym cyklu życia (1). Wartości czynników, jak i samego ryzyka zostały określone jako liczby rozmyte o trójkątnej funkcji przynależności $\mu(\mathrm{m}, \mathrm{a}, \mathrm{b})$, gdzie: $\mathrm{m}$ - wartość dominująca zmiennej o całkowitej przynależności, a,b - granice przedziału zmienności.

Procedurę oceny ryzyka można przestawić w następujących punktach:

1. Identyfikacja zagrożeń i określenie wartości prawdopodobieństwa ich występowania (rys. 1).

2. Określenie konsekwencji rozważanych zagrożeń - możliwe uszkodzenia lokalne i globalne skutki każdego z tych uszkodzeń (prawdopodobieństwa warunkowe uszkodzeń i stanów konstrukcji) oraz ich konsekwencje. 
3. Obliczenie wg wzoru (1) ryzyka dla poszczególnych zagrożeń oraz ryzyka będącego sumą poszczególnych wartości dla danych zagrożeń.

4. Porównanie wartości ryzyka z dopuszczalną dla danej konstrukcji wartością (kryterium akceptowalności ryzyka).

5. Ocena procentowego udziału ryzyka od poszczególnych zagrożeń i ich grup w wartości ryzyka całkowitego.

\subsection{Zagrożenia}

Zagrożenia (zdarzenia ekstremalne) można podzielić na związane z:

1. Procesem budowlanym
a) Błędy projektowe,
b) Błędy wykonawcze,
c) Błędy użytkowania i utrzymania obiektu.

2. Działaniami człowieka
a) Wypadki: wybuch gazu, uderzenie pojazdów, awarie,
b) Celowe działania człowieka.

3. Działania żywiołów
a) Powietrze: oddziaływanie huraganowego wiatru,
b) Woda: intensywne opady atmosferyczne, powodzie,
c) Ogień: pożary,
d) Ziemia: zmiany w gruncie, wstrząsy sejsmiczne i parasejsmiczne.

Prawdopodobieństwo wystąpienia danego zagrożenia zostało określone na podstawie liczby katastrof spowodowanych danym zdarzeniem ekstremalnym dla obiektów o żelbetowej konstrukcji szkieletowej (średnia, najmniejsza i największa liczba w roku) do ogólnej liczby budynków o rozważanej konstrukcji w Polsce (rys. 1).

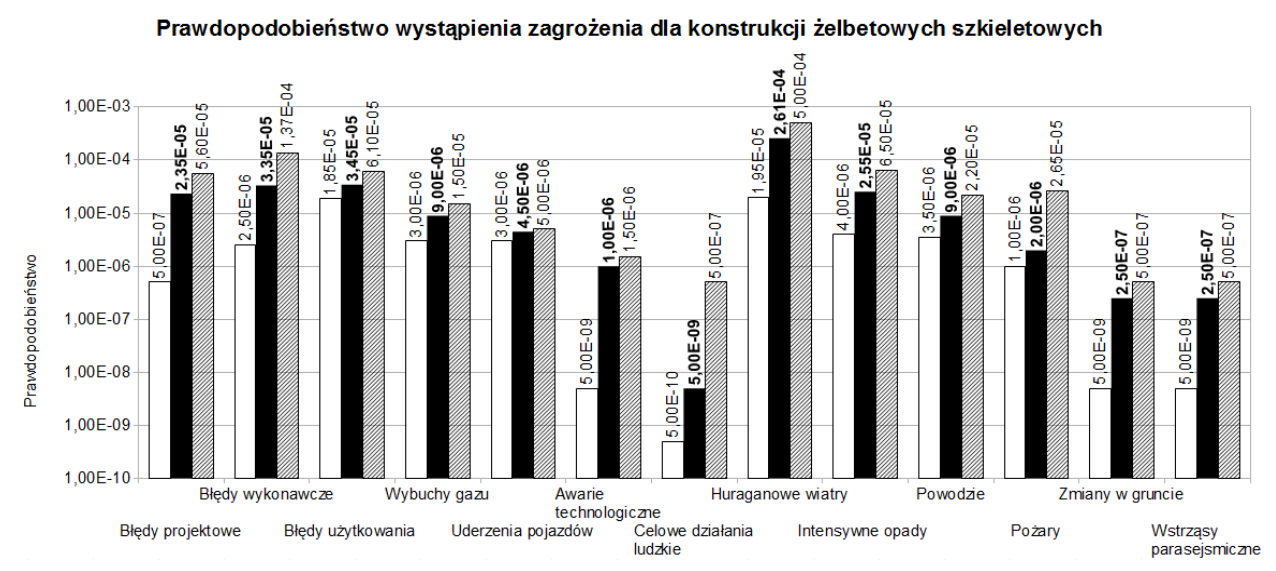

Rys. 1. Prawdopodobieństwo wystąpienia zagrożenia dla żelbetowych budynków szkieletowych

Fig. 1. Probability of threats for reinforced concrete frame building 


\subsection{Konsekwencje}

Przy szacowaniu poniesionych konsekwencji dla danego zdarzenia ekstremalnego należy:

- zidentyfikować zniszczenia lokalne (o niedużym zasięgu, jeden do kilku elementów) mogące powstać na skutek zdarzenia wyjątkowego (należy uwzględnić typ konstrukcji i charakter obciążenie wyjątkowego),

- określić możliwe globalne skutki jako stany konstrukcji po uszkodzeniu lokalnym (analiza numeryczna - modele globalne i lokalne, programy do dynamicznej analizy konstrukcji żelbetowych),

- oszacowanie konsekwencji (szacowane jako część kosztu inwestycji w całym cyklu życia): koszty zniszczenia, odbudowy, rozbiórki, koszty leczenia, ubezpieczeń, koszty społeczne, można przyjmować według tabeli 1.

W przypadku uszkodzeń lokalnych i globalnych skutków można posłużyć się pięciostopniową skala rozmyta prawdopodobieństwa ich wystąpienia (rys. 3a): $\mathrm{N}$ - brak L - niskie, $\mathrm{M}$ - średnie, $\mathrm{H}$ - duże, $\mathrm{S}$ - pewne $[9,10]$.

Tablica 1. Konsekwencje (wg [7] i kalkulacji własnej)

Table 1. Consequences (according [7] and own calculation)

\begin{tabular}{|c|c|c|c|}
\hline Konsekwencje & Zniszczenia (globalne skutki) & $\begin{array}{c}\text { Zagrożenie } \\
\text { życia } \\
\text { i zdrowia }\end{array}$ & $\begin{array}{c}\text { Koszty } \\
\text { względne }\end{array}$ \\
\hline Poważne & $\begin{array}{c}\text { zniszczenie części konstrukcji z wysoką } \\
\text { możliwością zawalenia }\end{array}$ & Poważne & powyżej 1,0 \\
\hline Wysokie & $\begin{array}{c}\text { zniszczenie części konstrukcji z wysoką } \\
\text { możliwością zawalenia }\end{array}$ & Duże & $0,25-1,0$ \\
\hline Średnie & $\begin{array}{c}\text { zniszczenie części konstrukcji, małe praw- } \\
\text { dopodobieństwo zawalenia }\end{array}$ & Małe & $0,10-0,25$ \\
\hline Niskie & miejscowe uszkodzenie & $\begin{array}{c}\text { Bardzo } \\
\text { niskie }\end{array}$ & $0,05-0,10$ \\
\hline Bardzo niskie & $\begin{array}{c}\text { miejscowe uszkodzenie } \\
\text { o małym znaczeniu }\end{array}$ & Brak & $0,01-0,05$ \\
\hline
\end{tabular}

\section{Przykład}

Analizowanym obiektem jest budynek o żelbetowej konstrukcji szkieletowej o wymiarach $16 \mathrm{~m} \times 16 \mathrm{~m} \times 12 \mathrm{~m}$ (rys. 2). Jest to obiekt użyteczności publicznej (galeria handlowa) zlokalizowany w Rzeszowie. Koszt budowy i utrzymania obiektu w całym projektowanym okresie użytkowania (50 lat) wynosi $5 \mathrm{mln}$ złotych. Szkielet konstrukcji stanowią monolityczne żelbetowe (beton klasy C30/37) słupy i rygle zbrojone stalą klasy C o granicy plastyczności równej $500 \mathrm{MPa}$. Zbrojenie i wymiary elementów przedstawiono na poniższym rysunku (rys. 2). Stropy zostały wykonane z prefabrykowanych sprężonych płyt kanałowych o grubości $150 \mathrm{~mm}$. Budynek zakwalifikowany jest do klasy konsekwencji 3 ze względu na dostęp do obiektu znacznej liczby osób [7]. 

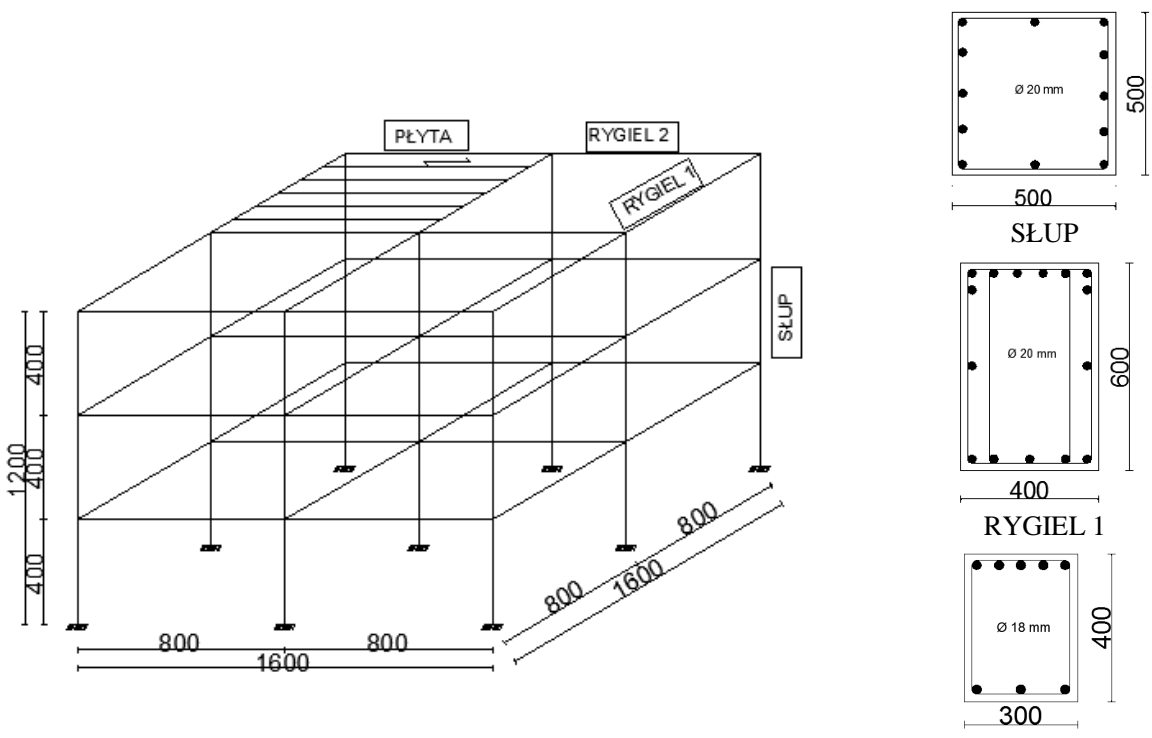

Rys. 2. Analizowana konstrukcja szkieletowa

RYGIEL 2

Fig. 2. Analyzed frame structure

\subsection{Zagrożenia}

Możliwe do wystąpienia zagrożenia zostały opisane w pkt. 2.2. Prawdopodobieństwo ich wystąpienia przedstawiono na wykresie (rys. 1).

\subsection{Konsekwencje}

Szacowanie konsekwencji przeprowadzono dla każdego zagrożenia za pomocą drzewa zdarzeń (rys. 3). Określono możliwe lokalne zniszczenia dla żelbetowych konstrukcji szkieletowych (zniszczenie ścian, płyt stropowych, rygli lub słupów) oraz prawdopodobieństwa ich wystąpienia zgodnie z zaproponowaną skalą ocen w pkt. 2.3. Dla każdego zniszczenia lokalnego przeanalizowano konstrukcję w celu określenia jego globalnych skutków. Uwzględniając różne lokalizacje lokalnych uszkodzeń oszacowywano prawdopodobieństwo globalnych skutków (skala ocen w pkt. 2.2.) oraz ich konsekwencje (tab. 1). 


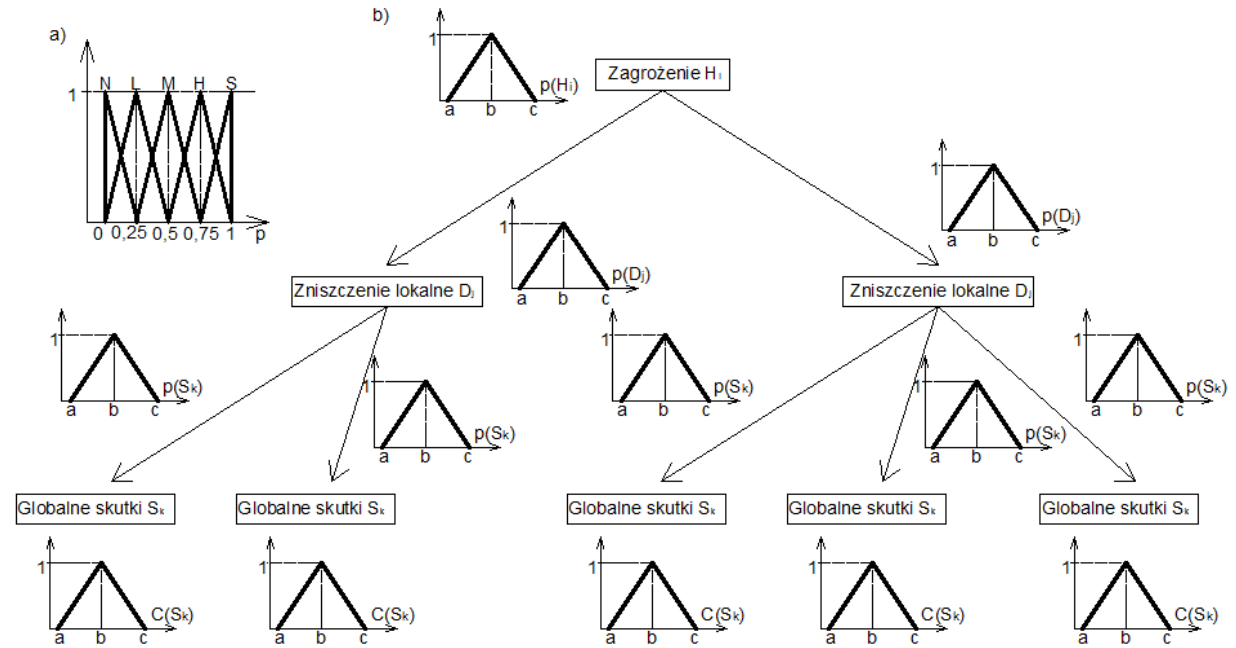

Rys. 3. Pięciostopniowa rozmyta skala ocen (a) oraz drzewo zdarzeń i funkcje przynależności (b)

Fig. 3. Five step fuzzy scale of estimation (a) and event tree and membership functions (b)

\subsection{Ocena ryzyka}

Za pomocą wzoru (1) oszacowano ryzyko dla poszczególnych zdarzeń ekstremalnych, ich grup oraz ryzyko całkowite. Wyniki przedstawiono na przedstawiono na poniższym wykresie (rys. 4).

Wartość ryzyka spowodowanego przez wszystkie zdarzenia ekstremalne przyjęto jako $100 \%$. Zdecydowanie większa część ryzyka pochodzi od zdarzeń związanych z procesem budowlanym, gdzie dominują błędy na etapie wykonawstwa.

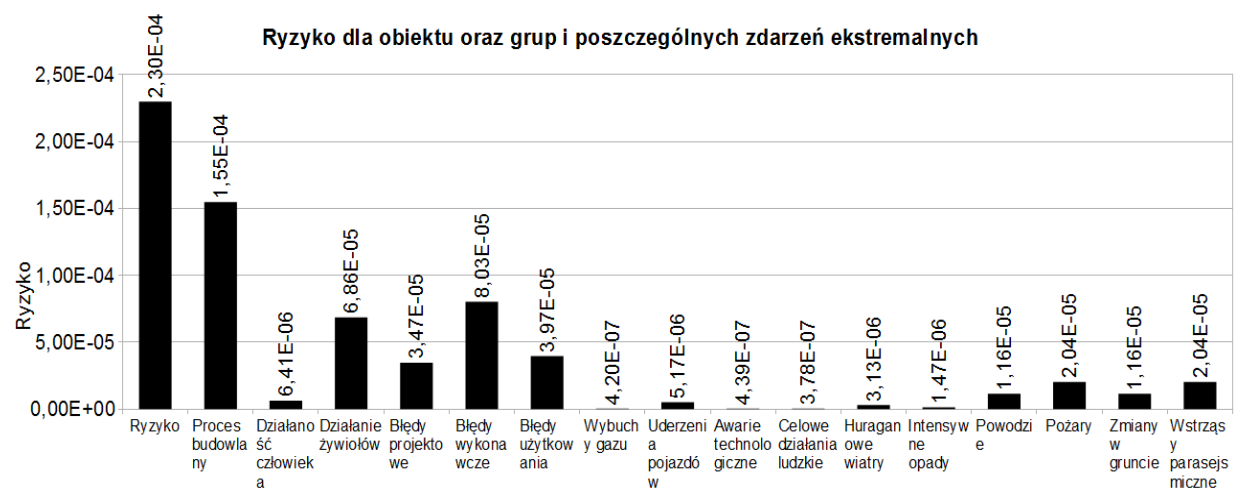

Rys. 4. Wartości ryzyka dla obiektu oraz grup i poszczególnych zdarzeń ekstremalnych

Fig. 4. Risk value for analyzed building, group and each extreme events 


\subsection{Analiza ryzyka}

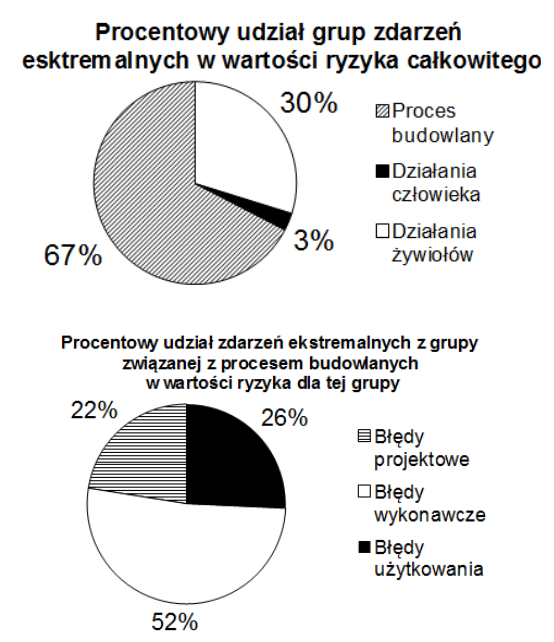

Rys. 5. Procentowy udział czynników ryzyka

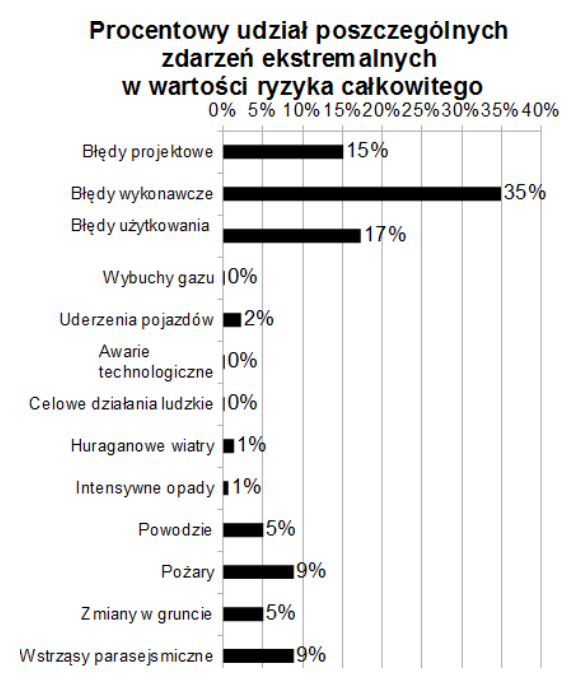

Fig. 5. Percentage of risk factors

Przeprowadzono analizę ryzyka mającą na celu porównanie wpływu poszczególnych zdarzeń ekstremalnych i ich grup na wartość ryzyka całkowitego. Rezultaty zostały przedstawione na wykresach (rys. 5). Potwierdza się stwierdzenie o dominującym znaczeniu zdarzeń związanych z procesem budowlanym, wśród których dominują błędy wykonawcze. Jest to związane $\mathrm{z}$ ich częstością występowania i możliwością wystąpienia niemal w każdym elemencie konstrukcji. Duży udział w wartości ryzyka mają także pożary, powodzie, wstrząsy parasejsmiczne. Spowodowane jest to dużymi konsekwencjami powstającymi na skutek wystąpienia tych zagrożeń.

\section{Wnioski}

W artykule przedstawiono procedury analizy i oceny ryzyka w odniesieniu do zdarzeń ekstremalnych dla żelbetowych konstrukcji szkieletowych. Umożliwia ona ocenę odporności konstrukcji na zdarzenia i ustalenie czynników ryzyka o największym wpływie na jego wartość. Po modyfikacji procedura może być $\mathrm{z}$ powodzeniem a w odniesieniu do innych konstrukcji. Istotną kwestią pozostaje także ustalenie kryterium akceptowalności ryzyka.

Zagrożeniem o największym prawdopodobieństwie wystąpienia są huraganowe wiatry, których konsekwencje są bardzo małe. Znaczne konsekwencje generowane są przez błędy na etapie projektowania, budowy i eksploatacji obiektu. Duży wpływ na ryzyko całkowite mają także zdarzenia katastrofalne związane $\mathrm{z}$ działaniem żywiołów, a wśród nich pożary, powodzie, zmiany w gruncie i wstrząsy sejsmiczne i parasejsmiczne. 


\section{Literatura}

[1] Baker J., Schubert M., Faber M.: On the assessment of robustness. Journal of Structural Safety, vol. 30, 2008.

[2] Bazy danych ITB, Katastrofy i awarie budowlane, http://www.awarie.jurek.waw.pl/, \{dostęp 19-05-2016\}.

[3] ISO Standard 13824:2009 General principles on risk assessment of system involving structures, ISO Geneve, 2009.

[4] JCSS, Risk Assessment in Engineering Principles, 2008: System Representation and Risk Criteria. ISBN 978-3-909386-78-9.

[5] Knoll F., Vogel T.: Design for robustness. Structural Engineering Documents, 11, IABSE, ETH Zurich, 2009.

[6] PN-EN 1990:2004 Eurokod: Podstawy projektowania konstrukcji.

[7] PN-EN 1991-1-7:2006 Eurokod: Oddziaływania na konstrukcje. Część 1-7: Oddziaływania ogólne oddziaływania wyjątkowe.

[8] Raporty GUNB, Katastrofy budowlane, http://www.gunb.gov.pl/, \{dostęp 19-052016\}.

[9] Woliński S., Defining of the structural robustness, Bulletin of the Polish Academy of Science, Vol. 61, No 1., 2013, pp.137-144.

[10] Woliński S., Projektowanie konstrukcji wspomagane analizą ryzyka, Budownictwo i Architektura, nr 13(2), 2014, str. 367-374.

\section{RISK ANALYSIS AND EVALUATION FOR REINFORCED CONCRETE FRAME STRUCTURES DUE TO EXTREME EVENTS}

\section{S u m m a r y}

Statistics of structures failures of in Poland give us information that the main reasons of building catastrophes are extreme events. This extreme events, which are not taken into account in designing, are unforeseen and difficult to predict. Their statistical description is highly uncertain and often impossible to recognize. Assessment of extreme events is important for public and multiapartment buildings. The paper presents procedures of risk analysis and evaluation for reinforced concrete frame structures, which are often used in public buildings in Poland. Risk is a combination of hazards and consequences, which can be generated by them. Due to the difficulties associated with the estimation of risk factors are treated as fuzzy numbers.

Keywords: quantitative risk analysis, qualitative risk analysis, risk factors, RC frame system

Przestano do redakcji: 07.06.2016 r.

Przyjęto do druku: 30.06.2016 r.

DOI: $10.7862 / \mathrm{rb} .2016 .34$ 